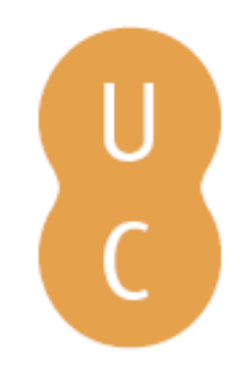

\title{
nommalina
}

\section{As Etiópicas de Heliodoro como cosmologia literária: a dramatização da narrativa e suas implicações hermenêuticas}

\author{
Autor(es): $\quad$ Mota, Marcus \\ Publicado por: Imprensa da Universidade de Coimbra; Annablume \\ URL \\ persistente: URI:http://hdl.handle.net/10316.2/40872 \\ DOI: $\quad$ DOI:https://doi.org/10.14195/978-989-26-1288-1_12 \\ Accessed : $\quad$ 26-Apr-2023 11:14:26
}

A navegação consulta e descarregamento dos títulos inseridos nas Bibliotecas Digitais UC Digitalis, UC Pombalina e UC Impactum, pressupõem a aceitação plena e sem reservas dos Termos e Condições de Uso destas Bibliotecas Digitais, disponíveis em https://digitalis.uc.pt/pt-pt/termos.

Conforme exposto nos referidos Termos e Condições de Uso, o descarregamento de títulos de acesso restrito requer uma licença válida de autorização devendo o utilizador aceder ao(s) documento(s) a partir de um endereço de IP da instituição detentora da supramencionada licença.

Ao utilizador é apenas permitido o descarregamento para uso pessoal, pelo que o emprego do(s) título(s) descarregado(s) para outro fim, designadamente comercial, carece de autorização do respetivo autor ou editor da obra.

Na medida em que todas as obras da UC Digitalis se encontram protegidas pelo Código do Direito de Autor e Direitos Conexos e demais legislação aplicável, toda a cópia, parcial ou total, deste documento, nos casos em que é legalmente admitida, deverá conter ou fazer-se acompanhar por este aviso.

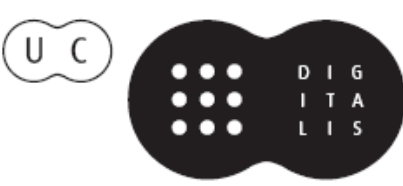




\section{Cosmópolis}

\section{mobilidades culturais às origens do pensamento antigo}

Gabriele Cornelli, Maria do Céu Fialho e Delfim Leão

\section{(coords.)}

IMPRENSA DA UNIVERSIDADE DE COIMBRA 


\title{
As ETIÓPICAS DE Heliodoro COMO COSMOLOGIA Literária: A Dramatização DA NARRATIVA E SUAS IMPLiCAÇÕES HERMENÊUTICAS ${ }^{\mathrm{I}}$
}

(Heliodorus' Aithiopika as a literary cosmology: drama, narrative, and hermeneutics)

\author{
Marcus Mota (marcusmotaunb@gmail.com) \\ Universidade de Brasília, Laboratório de Dramaturgia
}

\begin{abstract}
Resumo: Em sua obra As Etiópicas, Heliodoro procurou realizar um ambicioso projeto ficcional a partir de uma revisão da tradição textual helênica, produzindo a imagem de um cosmo, de uma totalidade que não se reduzisse à soma de suas partes. Para tanto, Intertextualidade, enciclopedismo e teatralidade são três procedimentos fundamentais desse projeto. Neste artigo, tais procedimentos são examinados e correlacionados, de modo a demonstrar como As Etiópicas se apresenta como um ponto de confluência e redefinição da cultura textual e material da Antiguidade.
\end{abstract}

Palavras-chave: Heliodoro; As Etiópicas; intertextualidade; enciclopedismo; teatralidade

Aвstract: Heliodorus' Aithiopika is an ambitious fictional project that produces a cosmic world based on the revision of the Hellenic textual tradition. In particular, Heliodorus uses three basic procedures: intertextuality, encyclopedism, and theatricality. In this paper, these procedures are examined and related to one another to demonstrate how Aithiopika seems to be a point of convergence and redefinition of the textual and material culture of Antiquity.

Keywords: Heliodorus; Aithiopika; encyclopedism; theatricality

\section{INTRODUÇÃo}

Em um de seus últimos textos, M. Bakhtin afirma que "o autor ao criar uma obra não a destina aos especialistas de literatura e não pressupõe uma compreensão científica dela, não almeja a criação de uma equipe de pesquisadores. Não convida os teóricos literários ao seu festim²". Para além da oposição entre tipos de leitores proposta, o corpus que reúne os exemplares restantes do que se convencionou chamar "romance grego" apresenta desafios interpretativos que apontam uma comunidade recepcional pluralizada. No caso de sua produção mais complexa, As Etiópicas, de Heliodoro, tal pluralismo pode ser depreendido na correlação entre os seguintes procedimentos composicionais: enciclopedismo, hibridismo cultural e teatralização narrativa.

\footnotetext{
${ }^{1}$ Este texto integra pesquisa de Pós-Doutorado financiada pela Capes e desenvolvida na Universidade de Lisboa sob supervisão da Profa. Dra. Marília Futre Pinheiro.

${ }^{2}$ Bakhtin 1992: 402.
} 
Ou seja, em As Etiópicas, temos uma longa narrativa que se organiza 1- na reelaboração de textos da tradição grega, como Épica Homérica, Tragédia Grega (Eurípides), Filosofia (Platão), História (Heródoto) entre outros gêneros e autores; 2- na justaposição de referências a indivíduos e grupos que apresentam diversos traços identitários, como provenientes do Egito, da Grécia, Etiópia, entre outros; 3- na apresentação de acontecimentos por meio de molduras teatrais, enfatizando que tudo o que se mostra é um evento observável por uma audiência.

Assim, As Etiópicas projeta uma força atrativa, convergente, como um livro sobre tudo, que não se resume a deleitar e a instruir. E se tudo existe para acabar num livro, conforme Mallarmé, As Etiópicas como livro dos livros - ou livro feito a partir de outros livros para que novos livros se produzam - encontra na teatralidade mais que um recurso escritural: no teatro, figuras e audiência se reúnem e se implicam mutuamente. Se ser homem é ter um mundo ${ }^{3}$, em Heliodoro, ser um leitor é mover-se nas aventuras imaginativas que sobrepõem culturas e formas de expressão. As Etiópicas nos oferece uma cosmologia literária que dramatiza a experiência da leitura. Problematizar estes temas será o foco deste trabalho.

\section{INTERTEXTUALIDADE}

$\mathrm{Na}$ recepção da Antiguidade, a oposição entre erudição e arte não é uma norma absoluta. Há um diálogo fundamental entre produção artística e transmissão da tradição que precisa ser melhor definido. A partir de uma compreensão mais clara das relações entre práticas culturais diversas muitas aproximações podem ser realizadas. Para tanto o caso de As Etiópicas, de Heliodoro, parece modelar.

Em uma crítica de fontes da obra de Heliodoro, mesmo que trabalhoso, é relativamente fácil determinar algumas relações intertextuais mais evidentes. Nessa crítica fica demonstrado a enorme presença de referências a Homero, especialmente, a Odisséia, e à dramaturgia ateniense ${ }^{4}$. A figura de Homero adquire um destaque todo especial: além do técnicas narrativas (In medias res, o retorno como horizonte narrativo, clímax e reconhecimento, unidades narrativas baseadas na alternância de dias e noites, referências topográficas, topoi literários, fraseologia e construção de personagens), o próprio Homero é textualizado em uma discussão sobre suas origens, sobre seu nascimento ${ }^{5}$.

Tais discussões alinham a escritura de Heliodoro aos empreendimentos e jogos intelectuais na Segunda Sofística, que, a partir da 'canocicidade de Homero', com ele estabelecem vínculos de reinvenção e paródia. Essa erudita familiaridade com Homero, da discussão de passagens textuais à proposição de

\footnotetext{
${ }^{3}$ Sousa 1981.

${ }^{4}$ Para uma lista das referências, v. Cueva 2004: 131-132. V. ainda Morgan \& Harrison 2008: 224-227 e Feuilltre 1966.

${ }^{5}$ Aethiopika 3.12.2. V. Whitemarsh 1998, Equihua 2012.
} 
abordagens interpretativas, engloba habilidades de lidar com minúcias filológicas e com a tradição clássica em toda a sua extensão, seja nas obras e autores, seja nas questões de sua recepção ${ }^{6}$. Se As Etiópicas pode, entre outras coisas, ser «a mais bem sucedida transformação literária da Odisséia do Império" 7, tal conquista situa Heliodoro como participante dessas práticas ao mesmo tempo que nos leva a reconsiderar a sua atividade como realizador de ficções.

Neste ponto, As Etiópicas se manifesta tanto como um produto dessa cultura textualista em tornos da recepção e transmissão dos clássicos, quanto uma obra que se integra ao cânone, por com ele estabelecer mais que relações de comentário e discussão intelectual. Simultaneamente As Etiópicas é uma obra de erudição e de artesania, aproximando ambos os universos.

\section{ENCICLOPEDISMO}

Como ler então As Etiópicas a partir dessa dupla chave? Inicialmente, está em cheque não a obra de Heliodoro, mas nossas premissas ao entrarmos em contato com narrativas. Para além do pressuposto da diferenciação estética que, segundo Gadamer postula uma distinção entre o mundo da arte e o mundo da vida, As Etiópicas não se resume a contar uma história ${ }^{8}$. Junto com as técnicas narrativas há todo um conjunto de referências e procedimentos interdisciplinares que conjugam as figuras e as cenas apresentadas a diversas áreas de conhecimento e ação. De forma que o caráter enciclopédico da narrativa demanda um enciclopedismo de sua recepção ${ }^{9}$.

Novamente Homero: em Íon, a figura de Sócrates questiona o rapsodo Íon quanto ao seu conhecimento de Homero. A seção central do monodiálogo socrático se concentra em interrogatórios nos quais são extraídos trechos em que aparecem atividades específicas como conduzir carros de cavalos, carpintaria, adivinhação, entre outras ${ }^{10}$. Ou seja, no texto homérico há referências a diversas ações que possuem seus próprios contextos, as quais podem ser reconhecidas e identificáveis como tais. Disto, o texto homérico possui essa marca de atravessar diversos campos de saber, de apresentar diversas atividades específicas, sem que por isso seja igualado a qualquer uma das atividades citadas. A amplitude da épica homérica se percebe na amplitude dos saberes e fazeres justapostos na narrativa.

Essa proto-enciclopédia não é apenas a transmissão de pressupostos de ação, como o queria Havelook ${ }^{11}$ : o que importa é a reflexibilidade do ato criativo

\footnotetext{
${ }^{6}$ Morgan \& Harrison 2008.

${ }^{7}$ Kim 2010: 19.

${ }^{8}$ Gadamer 1999.

${ }^{9}$ Desogus 2012. Sobre o conceito, v. Eco 1986, Eco 1984.

${ }^{10}$ Para a tradução do texto de Íon, v. Mota 2009.

${ }^{11}$ Havelook 1996. V. Para o conceito de proto-enciclopédia homérica v. König \& Woolf
} 2013. 
homérico, no qual a poematização de atividades específicas aponta para a própria atividade da poesia épica em reunir, integrar múltiplos contextos e referências. Essa poikilia como procedimento composicional não projeta um conteúdo ou uma instância transcendental responsável por unificar os materiais dispostos e justapostos no texto. Só foi possível louvar a ira de Aquiles quando houve a capacidade de se mostrar como se veste uma armadura, como se faz um cozido. Nesse sentido, fica supérflua a distinção entre o que é e o que não é ficcional, narrativo. Tudo é obra e a obra é justamente essa projeção heterogênea de atividades conjugadas no texto. A isso pode-se atribuir o caráter de ' enciclopédia'.

Em As Etiópicas tal procedimentos é explorado já a partir de um diálogo com a erudição em torno da recepção das de Homero e de outras obras da cultura greco-latina. A partir dessa organização multirreferencial, junto com a narrativa, com a sucessão de eventos e personagens, temos momentos da escritura no qual são não apenas nomes de pessoas e lugares são arrolados, como também há digressões sobre os lugares e acontecimentos referidos no texto ${ }^{12}$.

$\mathrm{Na}$ abertura do texto por exemplo, temos que:

"O dia mal acabara de brilhar sorrindo e o sol resplandecia no cume das montanhas quando um bando de ladrões armados passou a espiar a partir de cima do monte que se eleva ao longo de uma das bocas do Nilo, chamada de Heracleótica. Por instantes eles permaneceram examinando visualmente o mar em sua extensão abaixo deles. Primeiro lançaram os olhos sobre o oceano, mas, como não avistaram nenhuma embarcação que prometia saque ou roubo, volveram o olhar à praia à beira do mar. E isso foi o que viram ali."

A sucessão de imagens a partir do campo de observação da personagem coletiva dos grupo de bandidos é brevemente interrompida pelo aposto explicativo sobre o rio Nilo. Em meio a uma série de inderterminações que continuam além desse momento de abertura (quem são os bandidos? o que vêem? quem é a mulher que tem um homem ferido aos seus pés?), o único ancoramento é a ênfase no rio. $\mathrm{O}$ aposto especifica o lugar onde a narrativa se inicia.

Nos fragmentos restantes da obra perdida Geographika, o erudito (polímata) Eratóstenes de Cirene (285 a.C - 205a.C) ${ }^{13}$, após considerar Homero o pai da geografia, censura o performer épico por não conhecer as quais eram as bocas do rio Nilo ${ }^{14}$. Reagindo a tal desconhecimento, Eratóstenes detalha que na região de Canobo (Canopo) e Alexandria fica o último braço ou embocadura do delta

\footnotetext{
${ }^{12} \mathrm{~S}$. Bartsch associa essa produção de referentes aos exercícios retóricos- progymnasmatae lista trechos em que Heliodoro realiza tais exercícios. V. Bartsch 1989: 12-13.

${ }^{13}$ V. Suda, E2898. V. Vanusia 2001.

14 Eratóstenes fr. 10 (Roller 2010: 22).
} 
do Nilo, e que se chama canóbica ou heracleótica ${ }^{15}$. Esse detalhamento procura distiguir o empreendimento de Eratóstenes daquele do rapsodo. Homero teria conhecimento de regiões próximas, mas não de lugares que necessitassem longas viagens e viagens pelos mares ${ }^{16}$.

(Para uma visualização, de como seriam estas bocas do Nilo, eis a seguinte ilustração: ${ }^{17}$ )

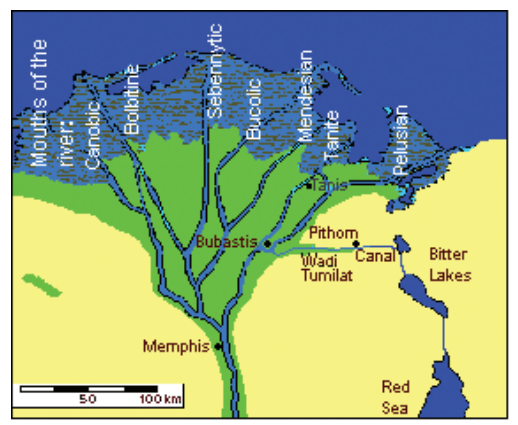

Tais afirmações e muitas outras do perdido livro de Eratóstenes manifestam uma polêmica para com Homero selecionada nos dois primeiros livros da Geografia, de Estrabão. O esforço de Eratóstenes em defender um campo de conhecimento distinto da autoridade da tradição poética acaba por, como Platão, em uma refutação do processo composicional do rapsodo como acesso a dados que são obtidos por meio da etnografia e do cruzamento de fontes orais e escritas. A refutação é feita por meio da seleção de trechos, com foco nas referências escritas e sua relação com efetivas fontes, registros, depoimentos e observações in loco.

Mas a situação fica mais complicada: explicitando essa polêmica entre modos de se construir discursos sobre o mundo, e posicionando-se contra Eratóstenes, Estrabão afirma que "Todo mundo acredita que sua poesia \{a de Homero\} é uma produção erudita (poiêsin philosóphêma), menos Eratóstenes que nos proíbe de julgar as ideias (diánoian) dos poemas e de buscar as referências históricas deles. ${ }^{1{ }^{\prime}}$ Não sendo investigações ou tratados eruditos, as obras de Homero são apenas fantasias ou falsidades.

Estrabão preludia suas investigações geográficas por um debate e refutação de Erátostenes que refutou Homero. Escrevendo quase dois séculos após seu predescessor, Estrabão apresenta uma obra monumental, dividida em 17 livros, em caráter enciclopedístico, sendo os dois primeiros capítulos a exposição dos métodos do livro por meio da crítica empreendimentos assemelhados e

\footnotetext{
${ }^{15}$ Eratóstenes Fr. 56 (Roller 2010: 75).

${ }^{16}$ Eratóstenes Fr. 8 (Roller 2010: 45).

${ }^{17} \mathrm{http}: / /$ www.waa.ox.ac.uk/XDB/tours/nile36.asp

${ }^{18}$ Eratóstenes Fr. 5 (Roller 2010: 75). V. Gardner 1977, Snowden 1970.
} 
reabilitação de Homero, e, partir do livro 3, descrição e discussão de lugares, povos e culturas reunidos por regiões ${ }^{19}$.

A cosmologia geocultural de Estrabão é uma réplica etnográfica da cosmologia literária de Homero, que em muito determinará o projeto ficcional de Heliodoro.

Voltando para o trecho de abertura de As Etiópicas, o detalhe do aposto situa o leitor em lugar que é confluência de culturas: os dois jovens enamorados que são alvos dos olhares de cobiça, fascínio e temor que os bandidos cintilam encontram-se no meio de sua aventura, nas margens do Egito, na parte mais meridional do Mediterrâeo. Enquanto os relatos paralelos fornecem os antecedentes da narrativa, o casal continua fisicamente no Egito até a Meroé, na Etiópia, região tida por Homero como lugar mais extremo da terra ${ }^{20}$. Dessa forma, o momento de abertura da narrativa de As Etiópicas é o meio do caminho, no Egito, do retorno à Etiópia. Nesse lugar onde se encontram os bandidos, os restos de um naufrágio e um anônimo casal, temos uma justaposição de lugares, culturas e histórias. A abertura in medias res é uma estrutura em camadas reunidas como uma enciclopédia multicultural: temos os bandidos egípcios, o casal misterioso que fala em grego e depois os acontecimentos finais na Etiópia. Assim, o movimento da narrativa vai em direção contrária ao da Odisséia: do centro para as margens, do helenocentrismo para os lugares finais da expansão.

Aqui a referência geográfica se defronta com a cronológica. A referência ao Nilo, além de localização questão espacial, ajuda a determinar a datação dos eventos representar, pois aqui e nos momentos seguintes não há referência à cidade de Alexandria, o que nos levar a propor como marcos temporais "a data entre a conquista do Egito em 525 a.C e a campanha de Alexandre o Grande no Egito ${ }^{21}$ " Ou seja, Heliodoro situa sua narrativa aproximadamente na Grécia Clássica, em um Egito ocupado pelos Persas. O naufrágio, os jogos interculturais no passado vinculam-se às questões identitárias que ocupam o projeto narrativo de Heliodoro, que se anuncia ao fim do livro (sphragis) como "um Fenício de Emesa" na Síria ${ }^{22}$.

Mobilizando todo um conjunto de referências clássicas e pós-clássicas, Heliodoro, vindo da periferia do Império Romano, entra em debate com o cânone ao reescrever a Odisséia em uma épica erótica, que coloca, ao fim de um trajeto iniciático, o primevo, o antigo, o periférico agora transformado, como a mística instância ideal. Cada vez mais distante da Hélade, o casal se integra em Meroé23.

\footnotetext{
${ }^{19}$ Estrabão mesmo defende o caráter enciclopédico de sua Geografia (1.1.12-14).

${ }^{20}$ Odisséia 1.21-25. Outras referências de Homero à Etiópia: Ilíada 1.423-424; Ilíada 23.205-207; Odisséia 4.81-84; Odisséia 5.281-287.

${ }^{21}$ Morgan 2007:483.

${ }^{22}$ Etiópicas 10.41.4. V. Hilton 2012, Peirano 2014.

${ }^{23}$ Whitemarsh 1999, Whitemarsh 2011.
} 


\section{Teatralidade}

Mas todas as questões geográficas, literárias, multiculturais se dão em uma moldura cênica. Todo o texto de As Etiópicas é atravessado seja por referências a termos relacionados a eventos teatrais, seja por disposição dos encontros personativos em um arranjo cênico ${ }^{24}$.

Novamente o aposto explicativo da abertura. Os bandidos se reúnem para ver que acontece ali na boca heracleótica como se estivessem em um teatro. $\mathrm{O}$ texto explicitamente marca o símile: "eles \{os bandidos\} estavam nos montes como a audiência em um teatro..$^{25}$ " A partir do elevado dos montes para o palco na praia se constroi uma organização espacial que distribui os partícipes do evento cênico homóloga ao arquitetura do teatro helenístico: os observadores distintos dos atores cercam a orquestra, como se vê nesta ilustração de Abraham Bloemaert (1625) ${ }^{26}$.

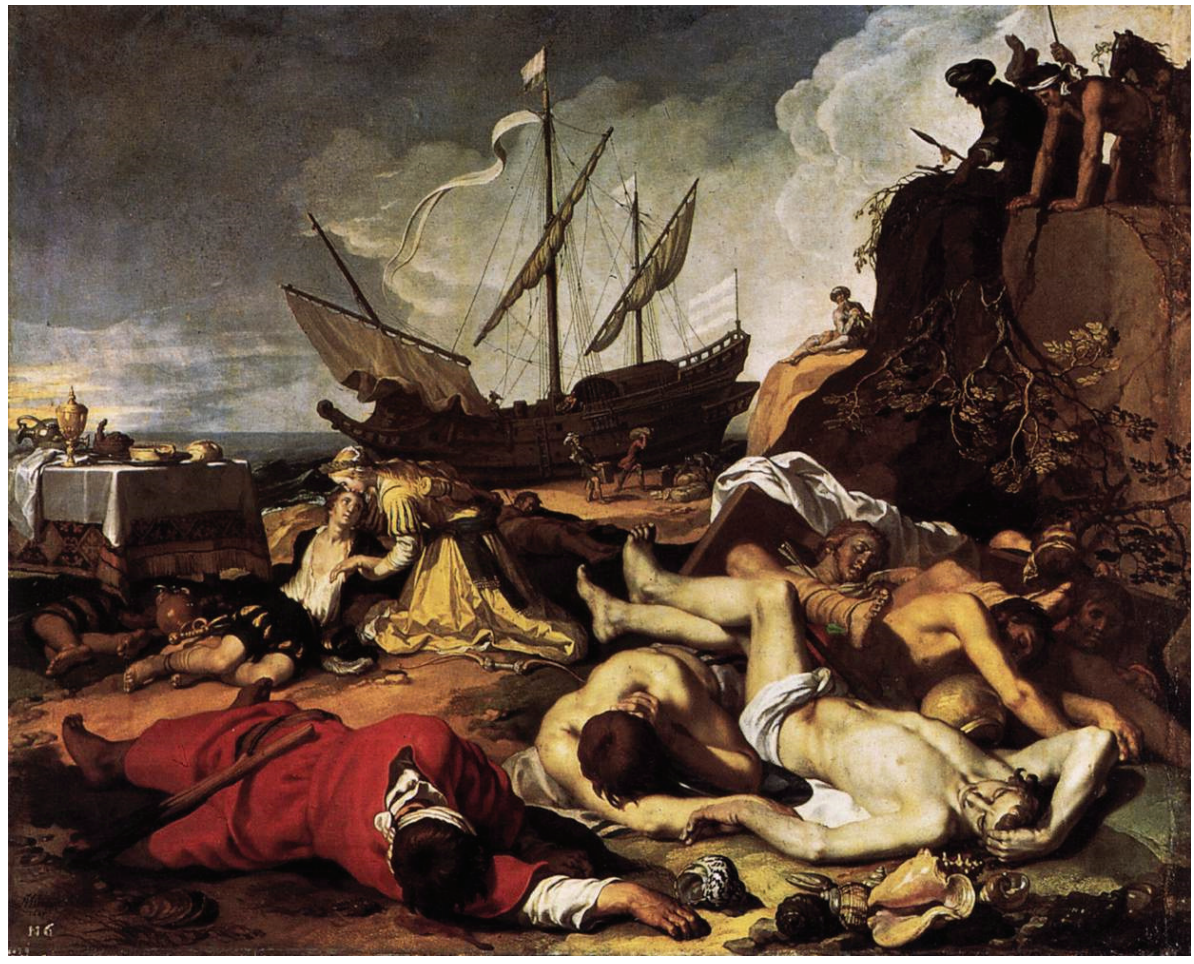

Usando o mesmo cenário, Sêneca escreve em Naturales Quaestiones (IV.a,13) que "Balbilo, um excelente homem perfecionado em todo tipo de literatura

${ }^{24}$ Bartcsh 1989, Calpe 2010, Mota 2013.

${ }^{25}$ Etiópicas 1.1.1.

${ }^{26}$ Link: http://commons.wikimedia.org/wiki/File:Abraham_Bloemaert_-_Charikleia_ and_Theagenes_-_WGA02275.jpg. 
inusitada afirma que, quando era prefeito do Egito, na boca heracleótica do Nilo, a maior de todas, assistiu a um espetáculo (spectaculo) de luta entre golfinhos que vinham do mar e uns crocodilos do rio. ${ }^{27}$ "

A partir da boca heracleótica do Nilo multiplicam-se não somente eventos organizados em homologia a espetáculos ou uso de vocabulário teatral para descrever encontros entre personagens: mais que metáforas ou exercícios retóricos, a questão da teatralização da narrativa heliodoriana consuma os tópicos previamente abordados.

A moldura cênica não se reduz a analogias ou a imagens do dispositivo teatral. Ampliando a questão, a ideia de uma reunião de díspares, de integração dos diversos e dispersos em um espaço é uma ideia-projeto que evidencia processos de retradicionalização, de contato criativo, de reinvenção da tradição.

Não mais o teatro, e sim a teatralidade, como procedimento de se tornar compreensiva essa intervenção e configuração da memória cultural. Novamente Homero, o pai dos tragediógrafos, em seu intergênero épico-dramático é o alvo $^{28}$.

Heliodoro ao posicionar uma audiência em sua narrativa, estabelecer um horizonte cênico para a construção de sua enciclopédia textual, projeta a participação do leitor em um grande teatro, em uma reunião maior que atravessa a grande narrativa que é As Etiópicas mas que não se resume à história contada. $\mathrm{O}$ recurso ao intergênero, à fronteira entre produções e tradições escriturais faculta o acesso a uma diversidade de protocolos de leitura, no entrechoque de estratégias de interpretação cujo resultado é de fato reside no teste, na perturbação mesma dessas estratégias e protocolos. Uma narrativa teatralizada estruturalmente, ou seja, organizada para produzir efeitos de reorientação das disposições e ações de sua recepção ao fim, toma como sujeito da narrativa não o narrado e sim o leitor. Se, como Homero, e ainda mais, Heliodoro em sua dramaturgia narrativa desloca a condução dos eventos para o acúmulos de justaposição de referências e mistério sobre o casal protagonista, por meio de um narrador que cede a prerrogativa de sua onisciência diversos narradores e cenas teatralizadas, temos o estabelecimento de uma experiência de leitura que demanda diversas habilidades outras que o seguir o fio da história.

Assim, a poderosa ideia que o evento teatral viabiliza - a construção de uma comunidade a partir de uma experiência recepcional ${ }^{29}$ - encontra em As Etiópicas mais que um expediente técnico-narrativo. Escrevendo no fim de uma época, o último dos romances gregos projeta a amplitude de um mundo instável, o centro político sendo devorado por suas margens, a ruína em meio ao sol que brilha,

\footnotetext{
${ }^{27}$ Aguilar 2006: 161-162.

${ }^{28}$ Expressão platônica em A República, 607a.

${ }^{29}$ Richtner 2011.
} 
As Etiópicas de Heliodoro como cosmologia literária: A dramatização da narrativa e suas implicações hermenêuticas

uma utopia - chegar a Meroé, ao passado antes do passado, fora da história mas a partir da história, fora de Homero e da Hélade, mas a partir da tradição revisitada ${ }^{30}$.

Em todo caso, atravessando séculos, obras e homens, a moldura cênica continua frente o mundo em colapso ou a uma nova ordem que se ergue, pois, em cena, continua o mínimo para que haja mundo: é um homem diante de outro, dois estranhos face a face.

${ }^{30}$ Whitemarsh 2011b. V. Ndione 2007/2008 sobre as relações entre Meroé e Aitbiopika. 


\section{REFERÊNCIAS BibLIOGRÁficas}

Aguilar, D. (2006), El panorama literario técnico-cientifico en Roma (Siglos I-II D.C.) "Et Docere et Delectare". Salamanca.

Arthos, J. (2013), Gadamer's Poetics: A Critique of Modern Aesthetics. Londres/ Nova York.

Bakhtin, M. (1992), "Epistemologia das Ciências Humanas", in Estética da Criação Verbal. São Paulo, 398-414.

Bartsch, S. (1989), Decoding the Ancient Novel. The Reader and the Role of Description in Heliodorus and Achilles Tatius. Princeton.

Calpe, M. (2010), "Les Etiópiques: La Novella com a parodia dels gèneres dramàtics", Studia Philologica Valentina 12.9: 105-117.

Cueva, E. (2004), The Myths of Fiction. Studies in the Canonical Greek Novels. Michigan.

Desogus, P. (2012), “The encyclopedia in Umberto Eco's semiotics”, Semiotica 192: 501-521.

Eco, U. (1986), Lector in Fabula. São Paulo.

Eco, U. (1984), «Metaphor, dictionary and encyclopedia”, New Literary History 15: 255-271.

Equihua, R. (2012), La influencia escolar en Las Etiopicas de Heliodoro. Tese de Doutorado: Universidade de Salamanca.

Feuilltre, E. (1966), Études sur les Éthiopiques d'Héliodore. Paris.

Gadamer, H.-G. (1999), Verdade e Método I. Petrópolis.

Gardner, J. (1977), "Blameless Ethiopians and other”, GER 24.2: 185-193.

Havelock, E. (1996), Prefácio a Platão. Campinas.

Hilton, J. (2012), "The sphragis of Heliodorus, genealogy in the Aithiopika, and Julian's Hymn to King Helios", Ágora 14: 195-219.

Kim, L. (2010), Homer Between History and Fiction in Imperial Greek Literature. Cambridge.

König, J. \& Woolf, G. (2013), Encyclopaedism from Antiquity to the Renassance. Cambridge.

Morgan, J. \& Harrison, S. (2008), "Intertextuality", in T. Whitmarsh (ed.), The Cambridge Companion to The Greek and Roman Novel. Cambridge, 218236.

Morgan, J.R. (2007), “Heliodorus” In: I. de Jong \& R. Nünlist, Time in Ancient Greek Literature. Leiden, 483-504.

Mota, M. (2008), A dramaturgia musical de Ésquilo. Brasília. 
Mota, M. (2009), "Performance e inteligibilidade: traduzindo Íon, de Platão", Archai 2: 183-204.

Mota, M. (2013), Nos Passos de Homero. Ensaios sobre performance, filosofia, música e dança a partir da Antiguidade. São Paulo.

Ndione, J. (2007/2008), Les Éthiopiques d'Heliodore: document historique sur Méroé oufiction romanesque. Tese de Doutorado, Université Nancy 2. Link: http:// docnum.univ-lorraine.fr/public/NANCY2/doc524/2009NAN21001.pdf

Peirano, I. (2014), “Sealing' the book.: the sphragis as paratext”, In L. Jansen (Org.) The Roman Paratext. Frame, Text, Readers. Cambridge.

Richter, D. (2011), Cosmopolis: Imagining Community in Late Classical Athens and Early Roman Empire. Oxford.

Roller, D. (2010), Eratosthenes' Geography. Fragments Collected and Translated, with Commentary and Additional Material. Princeton.

Snowden, F. (1970), Blacks in Antiquity. Ethiopians in the Greco-Roman Experience. Harvard.

Sousa, E. (1981), História e Mito. Brasília.

Strabo. (1912), Geography. Books IE II. H.L. Jones (trad.). Harvard.

Vanusia, P. (2001), The Gift of the Nile: Hellenizing Egypt from Aeschylus to Alexander. Berkeley.

Whitmarsh, T. (1998), "The birth of a prodigy: Heliodorus and the genealogy of Hellenism”, in R. Hunter (ed.), Studies in Heliodorus. Cambridge, 93-124.

Whitmarsh, T. (1999), "The rites of passage: cultural initiation in Heliodorus' Aitbiopika", in R. Miles, Constructing Identities in Late Antiquity. London, 16-40.

Whitmarsh, T. (2001), Greek Literature and the Roman Empire: the Politics of Imitatio. Oxford.

Whitmarsh, T. (2011a), Narrative and Identity in the Ancient Greek Novel: Returning Romance. Cambridge.

Whitmarsh, T. (2011b) "Hellenism, nationalism, hybridity: the invention of the novel”, in D. Orrells, G. K. Bhambra \& T. Roynon (eds.), African Athena: New Agendas. Oxford, 210-224. 